\title{
UM PARALELO ENTRE A CONCEPÇÃO POLÍTICO-FILOSÓFICA DE DEMOCRACIA DEFENDIDA POR ELÍAS DÍAZ E A CONSTITUIÇÃO FEDERAL BRASILEIRA DE 1988
}

\author{
José Mário Chaves Rêgo Filho 213
}

Recebido em: 13/08/2018

Aprovado em: 02/10/2018

\begin{abstract}
RESUMO
O presente artigo visa analisar a concepção político-filosófica de democracia defendida pelo filósofo espanhol Elías Díaz, qual seja, que democracia é incompatível com o sistema (neo)capitalista de produção. Por meio da averiguação desse postulado teórico, pretendese realizar um paralelo crítico com a Constituição Federal Brasileira de 1988, de modo a inferir sobre a (im)possibilidade de concretização de uma democracia no atual cenário jurídico-político brasileiro.
\end{abstract}

Palavras-chave: Democracia. (Neo)Capitalismo. Socialismo. Elías Díaz. Constituição Federal Brasileira de 1988.

\section{INTRODUÇÃO}

O Estado Brasileiro atravessa uma crise generalizada de legitimidade política, na qual o vocábulo democracia aparece nos discursos jurídico-políticos como tendo o condão de justificar tudo e todos. É possível vislumbrar que praticamente todos os políticos se declaram, quer adotem uma visão de esquerda, de centro ou de direita, democratas. É que a ideia de soberania popular confere, amiúde, uma aura de legitimidade à vida política contemporânea: todas as espécies de decisões estatais podem ser justificadas se passaram pelo crivo democrático.

Democracia, termo utilizado pela primeira vez por Heródoto, deriva de demokratia (governo do povo), cujas raízes são demos (povo) e kratos (governo). Numa acepção ampla, governo representa o poder político, enquanto o vocábulo povo tem correlação com aqueles que exercem tal poder. Neste último aspecto, não deixa de ser fecundo rememorar que a não

\footnotetext{
${ }^{213}$ Doutor em Direito pela Universidad Católica de Santa Fe - Argentina. Especialista em Direito Constitucional pela FEAD Minas - Centro de Gestão Empreendedora. Especialista em Direito Público pelo Centro Universitário Newton Paiva. Especialista em Ciências Criminais pela Universidade Candido Mendes. Mestrando em Direito Público-Penal pela Pontifícia Universidade Católica de Minas Gerais. Advogado criminalista.
} 
caracterização do sufrágio universal masculino e feminino abjura a noção de democracia, uma vez que ele é requisito indissociável para dar concretude à vontade da maioria.

Se a democracia assegura (ou deveria assegurar) a participação, direta ou indiretamente, da maioria do povo na tomada de decisões político-estatais, é factível dizermos que há uma democracia no Brasil?

Com o propósito de responder a essa pergunta, o presente texto pretende averiguar, com base nas concepções teóricas formuladas por Elías Díaz ${ }^{214}$, sobre a possibilidade de concretização de uma democracia em correlação ao cenário jurídico-político brasileiro. Para tanto, como não poderia ser diferente, serão analisadas as normas postas na Constituição Federal de 1988.

Elías Díaz, considerado por muitos pensadores como sendo o mais influente filósofo do Direito e da Política da Espanha no século XX, defendeu durante toda sua vida o que ele denomina ser a democracia real. Antes de explicitar a estrutura teórica em torno dessa concepção sustentada por Díaz, é imprescindível responder: por que adotar uma democracia política $^{215}$ ? Em outras palavras, por que a maioria dos membros da coletividade deve tomar as decisões estatais? $?^{216}$

Em conformidade com as formas de governo relatadas pela doutrina contemporânea, pode-se descrever três modos distintos de tomadas de decisões estatais: 1) apenas uma pessoa decide pelo todo (monarquia); 2) um grupo de indivíduos privilegiados (seja em razão da riqueza, da força física, da capacidade intelectual etc.) tomam as decisões que afetarão à coletividade (aristocracia); e, por fim, 3) a maioria do povo de uma determinada sociedade delibera, direta ou indiretamente, sobre os múltiplos assuntos que tocam a todos as pessoas da população (democracia). (RODRÍGUEZ, 2004, pp. 32-35, 154-156 e 431-434).

Nesse contexto das formas de governo, Díaz (1990, pp. 40-53; 1982a, p. 63) preleciona que a melhor solução contra o abuso de poder, embora melhor não implique ser algo infalível ou necessariamente justo, é participação da maioria das pessoas na tomada de decisões do Estado. ${ }^{217}$ Em uma sociedade, amiúde, alguém terá que estipular o que é mais

\footnotetext{
${ }^{214}$ Elías Díaz foi catedrático de Filosofia do Direito da Universidade Autónoma de Madrid e professor na Universidade de Pittsburgh (EUA). É doutor em Direito pela Universidade de Bolonha (Itália) e doutor honoris causa por diversas instituições, dentre elas a Universidade Carlos III de Madrid e a Universidade de Milão. ${ }^{215} \mathrm{O}$ uso do termo política neste contexto não é redundante, haja vista que Elías Díaz informa haver três tipos possíveis de democracia: a democracia como moral, a democracia política e, ainda, a institucionalização jurídica da democracia - o Estado de Direito. (DÍAZ, 2013, pp. 90-91).

${ }^{216}$ Sobre o tema, é interessante observar a irônica opinião de Churchill (apud BONAVIDES, 2011, p. 286): "A democracia é a pior de todas as formas imagináveis de governo, com exceção de todas as demais que já se experimentaram." 216

${ }^{217}$ A título de ilustração, insta mencionar que essa é a mesma posição político-ideológica defendida por Norberto Bobbio (1983, pp. 82-86; 2006, pp. 43-44).
} 
justo, mais conveniente e acertado para um determinado grupo social. A questão crucial é definir a quem competirá esta tarefa de enorme responsabilidade? Segundo Díaz (1984, pp. 58-59), a resposta é clarividente: compete a todos. As pessoas devem decidir, opinando livremente, sobre o que é melhor para todos e cada um deles.

O critério democrático é inegavelmente o mais adequado para definir o que é melhor para toda a coletividade, ao invés de delegar tal tarefa a um só homem supostamente excepcional ou a uma minoria de sábios ou espertos. (DÍAZ, 1982a, p. 58; 1977, pp. 130131). Se perscrutarmos as sociedades modernas notaremos que os melhores intérpretes do interesse coletivo são os próprios interessados.

Ademais, o processo de decisão democrática é o que mais se aproxima do processo de decisão ética (autonomia moral) e, por consequência, o que contém a maior e melhor possibilidade para a atuação e a realização das autonomias individuais. Por isso, é o mais ético, o mais justo. (DÍAZ, 2011, p. 76).

Vis-à-vis com essa realidade, com a necessidade do método democrático, Elías Díaz começa a explicitar o que ele caracteriza como "democracia real".

\section{DEMOCRACIA REAL}

Em consonância com que foi exposto anteriormente, Elías Díaz (1998, p. 94) é enfático ao argumentar que o método mais funcional, eficaz, justo e legítimo para saber o que um grupo social, sempre plural e com conflitos internos, considera como de sua vontade, é por meio da democracia. Por conseguinte, segundo ele, esta é a forma de governo mais acertada para trasladar, via Estado, demandas e interesses a normas jurídicas.

Se democracia é o método preferível e mais adequado, como saber se uma determinada sociedade é democrática? Em outras palavras, como perceber se há uma democracia real e não meramente uma previsão jurídico-formal? De acordo com Díaz (1976, p. 85), há um real pluralismo político, uma democracia real, quando de fato todos os cidadãos participam, direta ou indiretamente, da tomada de decisões estatais. Nas palavras de Díaz:

A democracia exige participação real das massas; pode nesta perspectiva definir-se a sociedade democrática como aquela capaz de instaurar um processo de efetiva incorporação dos homens, de todos os homens, nos mecanismos de controle das decisões [...]. (DÍAZ, 1975, p. 141, tradução nossa). 
Essa participação deve pressupor liberdade, é dizer, o direito de cada um expor livremente sua vontade. Sem liberdade não há democracia, nem legitimidade democrática ou soberania popular.

[...] A livre expressão da vontade individual é o fato, e o valor (critério ético, pois, de caráter humanista), que está subjacente à livre expressão da vontade coletiva em que consiste a soberania popular. (DÍAZ, 1984, p. 70, tradução nossa).

É preciso enfatizar que para configuração de uma democracia real é vital a presença de uma liberdade crítica, pois, apesar do método democrático ser o mais legítimo, não significa que as decisões da maioria sejam - a todo tempo - justas. A maioria pode equivocar-se e, $a$ posteriori, notar que realizou uma escolha errônea. Porquanto, os cidadãos devem ter senso crítico em relação às decisões político-estatais por eles (ou por outros, no passado) já efetuadas, de forma que, crendo ter havido uma falha, devem corrigi-la. Desse modo, a liberdade crítica é requisito indissociável da democracia. (DÍAZ, 1984, p. 60; 1976, p. 85; 1977, p. 133). A soberania popular se constrói e se fortifica por meio da crítica de todos exercida de modo constante. (DÍAZ, 1984, p. 58).

Todavia, a democracia não é somente, embora também, questão de liberdade, senão que é da mesma maneira questão de igualdade. (DÍAZ, 1976, p. 93; 1977, p. 140).

Elías Díaz explica que para concretização da plena liberdade humana é indispensável haver igualdade material, pois, sem esta, aquela não é de fato alcançável. Se uma sociedade é injusta, tendo grandes desigualdades sociais, os que têm menos recursos econômicos não têm acesso a exercer verdadeiramente suas liberdades, mesmo que elas existam de maneira jurídico-formal. No que toca a política, um cidadão com, por exemplo, baixa renda, não consegue efetivamente concorrer a um alto cargo eletivo, haja vista que sua condição econômica o retira do jogo político atual.

Sem igualdade, o direito à liberdade é apenas uma utopia: 1) de que adianta a liberdade de ir e vir para quem não tem condições econômicas para se deslocar?; 2) de que serve o direito de consumir (uma liberdade) para quem não tem condições de exerce-lo?; 3) de que vale para o cidadão pobre o direito de se candidatar a um cargo eletivo, se o concorrente rico utiliza todos os meios de comunicação para captar os votos? 
As desigualdades construídas pelo sistema capitalista de produção acarretam distribuição desnivelada dos "recursos políticos"218. A discrepância desses recursos ocasiona desigualdade, uma vez que alguns cidadãos adquirem mais influência do que outros.

Nessa diretriz, não é suficiente a democracia jurídico-política, senão que é fundamental uma democracia econômico-social. (DÍAZ, 1977, p. 139). Até porque o critério das maiorias somente será efetivo, no momento que as maiorias se tornarem dominantes, o que pressupõe uma igualdade material. (DÍAZ, 1976, p. 93).

Por meio dessa fundamentação teórica, Elías Díaz defende que democracia é inalcançável em ambiente (neo)capitalista, é dizer, democracia real somente é factível em modelos de sociedade com igualdade social, algo historicamente inexequível pelo (Neo)Capitalismo. Basta recordar que o "Capitalismo Clássico" veio ao mundo em substituição ao sistema feudal ${ }^{219}$, logo, a sociedade que antes era dividida por estamento ${ }^{220}$, passou a ser dividida em classes - divisão feita/medida por meio das riquezas materiais dos indivíduos. A bem da verdade, “[...] se se considerar a época da escravatura, a do feudalismo ou a do capitalismo, observa-se nelas um fenômeno permanente: a exploração, por aqueles que possuem, daqueles que nada possuem. " (DAVID, 1998, p. 158). Inclusive, nesse sentido, Karl Marx e Friedrich Engels pontuavam que:

A moderna sociedade burguesa, surgida das ruínas da sociedade feudal, não eliminou os antagonismos entre as classes. Apenas estabeleceu novas classes, novas condições de opressão, novas formas de luta em lugar das antigas. (MARX; ENGELS, 2011, p. 46).

Dessa forma, como poderia haver, em um ambiente (neo)capitalista, participação real da maioria dos cidadãos na produção da decisão política? Notem: O Capitalismo é nada mais nada menos do que a dominação de alguns grupos (algumas classes) sobrepondo às demais, ou seja, esse Sistema representa exatamente a dominação político-econômica de um grupo frente aos demais indivíduos - as classes desfavorecidas/espoliadas. Por conseguinte, democracia real e (Neo)Capitalismo não são termos conciliáveis.

Democracia exige participação factual das massas no controle das decisões e, igualmente, nos rendimentos da produção. Ausentes essas características integrantesnecessárias, não há sociabilidade democrática. (DÍAZ, 1975, p. 143).

\footnotetext{
${ }^{218}$ Considerando "recursos políticos" tudo que uma determinada pessoa ou um grupo social tem acesso, podendo intervir direta ou indiretamente na conduta de outras pessoas, exemplos: dinheiro, riqueza, recursos produtivos, rendimentos, status, informação, conhecimento, acesso aos meios de comunicação etc.

219 Aspecto primordial: sistema onde as relações de produção são marcadas pelo trabalho servil em favor dos "senhores feudais": nobreza e clero.

${ }^{220}$ Ou seja: a sociedade é dividida pelo "status" e pela honra; havendo pouca mobilidade social. Todavia, é mais aberta que a organização social em castas, porém mais fechada que a atual - em classes.
} 
A democracia deve ser entendida, portanto, como dupla participação (livre e de todos): primeira, participação na formação e na tomada de decisões jurídico-políticas; segunda, participação na produção e na distribuição dos resultados, medidos tanto em relação à satisfação de necessidades, como no reconhecimento de direitos e de liberdades. (DÍAZ, 2013 , p. $88 ; 1998$, p. $108 ; 2004$, p. $68 ; 2011$, p. 76).

Enquanto a democracia exige igualdade social, o (Neo)Capitalismo, com sua concentração monopolista de riqueza em poucas mãos, produz e alimenta as desigualdades sociais. (DÍAZ, 1975, p. 155). Esse descompasso parece ser estimulado, ou pelo menos perpetuado, em razão da grande influência do pensamento elitista na sociedade, defendendo que o mundo se compõe de duas classes de pessoas: uns, os seletos, os egrégios, a elite; outros, o rebanho, a horda, a ralé, a massa irracional e estúpida. (DÍAZ, 1975, p. 148).

Defronte com esse paradigma, frente à impossibilidade de compatibilizar coerentemente democracia e (Neo)Capitalismo, é premente conciliar, então, democracia com Socialismo. (DÍAZ, 1975, p. 129). Afinal,

a radical transformação das relações de produção que está na base do socialismo se
dirige a lograr a instauração de uma sociedade na qual se logre a incorporação e
participação real de todos os homens, em especial daquelas classes sociais que antes
viviam mais escravas do capital. A liberdade-participação substitui assim à
liberdade-alienação do capitalismo liberal. (DÍAZ, 1975, p. 171, tradução nossa).
O passo do capitalismo ao socialismo aparece, portanto, uma vez mais, como o
passo da democracia formal à democracia real. (DÍAZ, 1975, p. 145, tradução
nossa).

Com a superação do domínio privado dos meios de produção, o Socialismo possibilita lograr efetiva realização dos direitos humanos para todos os homens, rompendo com a divisão classista da sociedade capitalista. O homem deixa de ser objeto do capital, tornando-se livre. Todavia, o controle coletivo da propriedade não é - por si só - essa grande panaceia para todos os males, não deixando de estar exposto ao grave risco de torna-se burocrático e totalitário. Por essa razão, Elías Díaz (1977, p. 144) pontua que se não quisermos reviver os tempos do colapso da experiência do Socialismo real (século XX), este modelo políticoeconômico deverá respeitar os direitos básicos de liberdade crítica e de participação popular na produção da decisão política, ou seja, deve ser um socialismo democrático.

Díaz explica o sentido fundamental do socialismo democrático da seguinte maneira:

[...] Uma teoria e uma prática aptas para lograr em um país transformações reais de caráter socialista (propriedade e produção sob controle coletivo), mas dentro sempre do respeito à livre decisão democrática das maiorias e aceitando, com certeza, a revisão e confrontação periódica de tal decisão. (DÍAZ, 1976, p. 99, tradução nossa).

De maneira geral, essa é a concepção político-filosófica de democracia defendida pelo jusfilósofo espanhol Elías Díaz, qual seja, incompatibilidade do método democrático com o 
sistema (neo)capitalista de produção e, por consequência, uma aproximação lógico-necessária com o Socialismo.

\section{DEMOCRACIA, CAPITALISMO E A CONSTITUIÇÃO FEDERAL BRASILEIRA DE 1988}

Já faz três décadas que Elías Díaz vem defendendo, com todo afã político-acadêmico que lhe é peculiar, a concretização de uma democracia real nas sociedades contemporâneas. Consoante visto, o paradigma que ele pretende alcançar - com o foco de auferir concretude dos direitos humanos para todos os homens - é o do socialismo democrático. Nesse cenário, conforme restou claro por meio dos ensinamentos de Díaz, democracia e capitalismo são sistemas amplamente contrastantes.

Realizado esses esclarecimentos, a partir de agora examinar-se-á sobre a existência de uma democracia real no contexto brasileiro, tendo como ponto de análise as concepções político-filosóficas postuladas por Díaz e, do outro lado, a Constituição Federal de 1988.

De acordo os anseios jurídico-ideológicos postos pelo constituinte originário, o Brasil é um Estado Democrático. Essa previsão, além de ser parte integrante do preâmbulo, está expressa em várias passagens distintas na Constituição da República, em especial no parágrafo único do art. $1^{\circ}$ : "Todo o poder emana do povo, que o exerce por meio de representantes eleitos ou diretamente, nos termos desta Constituição.” Em relação à forma do exercício desse poder, a $\mathrm{CF} / 88$ positivou as seguintes diretrizes:

Art. 14. A soberania popular será exercida pelo sufrágio universal e pelo voto direto e secreto, com valor igual para todos, e, nos termos da lei, mediante:

I - plebiscito;

II - referendo;

III - iniciativa popular.

Conforme evidenciado nas normas postas pelo constituinte brasileiro, tem-se, pelo menos em tese, uma democracia no Brasil. ${ }^{221}$ No entanto, o simples fato de haver previsão constitucional de um instituto não implica que ele verdadeiramente exista. Um poeta pode narrar afirmando que a lua é lilás, mas isso não implica que ela realmente tenha essa coloração. Igualmente acontece no campo jurídico. A Constituição Federal pode positivar um determinado instituto, porém isso não acarreta a existência factual dele.

221 Afirmando ser o Brasil um Estado Democrático temos, por exemplo, Ricardo Arnaldo Malheiros Fiuza e Mônica Aragão Martiniano Ferreira Costa (2007, pp. 97-98). 
É facilmente observável na doutrina que grande parcela dos constitucionalistas brasileiros se contenta em realizar uma análise acrítica das questões correlatas à soberania do povo: 1) seja porque declaram que a $\mathrm{CF} / 88$ trouxe expressamente os postulados de uma democracia, não levando em consideração às demais normas constitucionais que porventura possam frenar a concretização deste instituto, ou seja, eles não realizam uma interpretação integral da Constituição; 2) ou, o que é demasiadamente comum, apenas analisam as normas postas (a vigência), sem levar em conta se elas estão sendo efetivas (eficazes), o que acaba isolando o Direito da realidade social, ao invés de abrir-lhe os caminhos.

Em conformidade com o analisado, a $\mathrm{CF} / 88$ declarou que as decisões estatais serão exercidas, direta ou indiretamente, pela maioria dos membros da sociedade, resguardado o direito ao sufrágio universal. Em outros termos, o nosso constituinte originário positivou uma democracia. Não obstante, em diversos dispositivos também previstos na $\mathrm{CF} / 88$, em especial naqueles relativos à Ordem Econômica, o constituinte brasileiro estabeleceu o sistema capitalista de produção ${ }^{222}$.

Kildare Gonçalves Carvalho (2006, p. 1325), ao analisar o artigo 170 da Constituição, principal norma disciplinadora da Ordem Econômica Brasileira, pontua que: “A opção do texto constitucional, embora não o diga expressamente, é pelo capitalismo e a apropriação privada dos meios de produção [...]."

De forma parecida, o constitucionalista José Afonso da Silva, comentando a Ordem Econômica instituída na atual Constituição brasileira, ensina que:

\begin{abstract}
Aqui, como no mundo ocidental em geral, a ordem econômica consubstanciada na Constituição não é senão uma forma econômica capitalista, porque ela se apoia inteiramente na apropriação privada dos meios de produção e na iniciativa privada (art. 170). Isso caracteriza o modo de produção capitalista, que não deixa de ser tal por eventual ingerência do Estado na economia; nem por circunstancial exploração direta de atividade econômica pelo Estado e possível monopolização de alguma área econômica, porque essa atuação estatal ainda se insere no princípio básico do Capitalismo, que é a apropriação exclusiva por uma classe dos meios de produção, e, como é essa mesma classe que domina o aparelho estatal, a participação deste na economia atende a seus interesses.

A atuação do Estado, assim, não é nada mais nada menos do que uma tentativa de pôr ordem na vida econômica e social, de arrumar a desordem que provinha do Liberalismo. Isso tem efeitos especiais, porque importa impor condicionamentos à atividade econômica, do quê derivam os direitos econômicos, que consubstanciam o conteúdo da Constituição econômica. Mas daí não se conclui que tais efeitos beneficiem as classes populares. Sua função consiste em racionalizar a vida econômica, com o quê se criam condições de expansão do Capitalismo, se é que tudo já não seja efeito deste. (SILVA, 2012, p. 719).
\end{abstract}

\footnotetext{
${ }^{222}$ Nesse sentido, é a afirmação de Celso Ribeiro Bastos e Ives Gandra Martins (2000, p. 16): “Do contexto [artigo 170, caput, da CF] extrai-se que o Brasil se filia ao modelo capitalista de produção, também denominado 'economia de mercado' [...]".
} 
Antes de continuar, insta salientar que, em verdade, não há no Brasil um mero Capitalismo - nos moldes clássicos. Atualmente, é possível observar um novo modelo do sistema capitalista de produção, que - por convenção - ficou denominado de Neocapitalismo. Este hodierno sistema representa:

[...] O nôvo modus operandi do sistema capitalista, cujas características específicas decorrem de necessidades orgânicas do próprio capital, bem como da tentativa do sistema responder ao desafio do progresso mundial das fôrças anticapitalistas [...]. (PEREIRA, 1971, p. 88).

Mesmo tendo sofrido algumas transformações, a essência do Sistema se mantem, isto é, continua sendo representado pelos mesmos valores. Ademais, vale lembrar que a superficial e aparente "socialização" produzida pelo sistema neocapitalista não se assemelha com o Socialismo. (DÍAZ, 1975, p. 131).

Assim sendo, se a escolha do constituinte foi pelo Neocapitalismo, é possível vislumbrar um enorme impasse, um verdadeiro imbróglio, não meramente jurídico, senão que igualmente político e social, afinal, conforme ensina Elías Díaz, democracia não se concretiza em ambiente neocapitalista.

As Constituições Liberais desconjuntam os direitos políticos dos econômicos, criando a ficção de que o acesso aos primeiros compensa a supressão dos segundos. Ademais, o sistema liberal econômico, "tutor" do capitalismo, garante tão somente uma suposta igualdade inicial para todos, que vertida numa igualdade jurídico-formal logo se transforma numa desigualdade real. ${ }^{223}$

Noutro giro, proclamar que o Brasil é formado por uma sociedade de massas não indica que também o seja, por consequência, democrático. "Sociedade de massas e sociedade democrática são termos que podem perfeitamente não coincidir”. (DÍAZ, 1975, p. 141, tradução nossa). O cerne da questão é que nas sociedades capitalistas, "de massas ou não", um determinado grupo social, formado pelos membros das classes privilegiadas, é que toma as decisões estatais, não havendo participação real da maioria dos homens no controle políticodecisório. Porquanto, sem uma democracia socioeconômica, a democracia política é inalcançável, e as decisões se tornam nessa situação duplamente antidemocráticas: são tomadas pelas classes economicamente favorecidas e respondem aos interesses predominantes dessas mesmas classes beneficiadas. (DÍAZ, 1975, p. 128).

223 Gustav Radbruch (2010, p. 99) ensinava que: "Uma igualdade meramente jurídico-formal significa dissimulação e aprofundamento da desigualdade social. A liberdade de propriedade igual para todos se converte na realidade, para os proprietários dos meios de produção, de mero domínio sobre as coisas em domínio sobre os homens, e, para as classes sem posses, em subordinação". 
Ao contrário da democracia liberal-capitalista (sufrágio universal como mera aparência de igualdade), o socialismo democrático (ou democracia socialista) com sua mais equânime distribuição de riquezas, converte o poder formal de participação em poder material, alcançando, inclusive, o seu propósito final: maior igualdade entre os homens.

\title{
4 CONSIDERAÇÕES FINAIS
}

Em um primeiro momento deste artigo foi examinada a concepção político-filosófica de democracia estabelecida por Elías Díaz, que por sua vez defende, de maneira críticoargumentativa, a incongruência entre soberania popular e (Neo)Capitalismo. Posteriormente, após analisar a Constituição Federal de 1988, ficou evidenciado que o constituinte brasileiro tentou - a princípio - fazer do Brasil um Estado Democrático. Contudo, foi possível notar que a $\mathrm{CF} / 88$ positivou, ao lado do intuito de estabelecer uma democracia, um modelo neocapitalista de produção. Com base nos postulados político-teóricos de Elías Díaz é possível asseverar que tal fato é algo confrituoso, é dizer, soberania da maioria dos cidadãos não se compatibiliza com Neocapitalismo.

Nessa vertente de pensamento, o Brasil, por ter adotado um sistema neocapitalista, não pode ser considerado, por consequência lógica, um Estado Democrático. Inclusive, no que toca a formação das leis, vale recordar que:

\begin{abstract}
A lei sempre emana do Estado e permanece, em última análise, ligada à classe dominante, pois o Estado, como sistema de órgãos que regem a sociedade politicamente organizada, fica sob o controle daqueles que comandam o processo econômico, na qualidade de proprietários dos meios de produção. (LYRA FILHO, 1999 , p. 8)
\end{abstract}

Essa conclusão vale igualmente aos atos emanados pelo Poder Executivo, eis que as decisões políticas tomadas são factualmente controladas pelas classes privilegiadas. Afinal, o Neocapitalismo outorga direitos e liberdades - de fato - apenas às classes sociais que dominam o aparato estatal. Dessa feita, as classes desfavorecidas, que são a maioria, ficam descartadas da seara político-decisória. Até porque, vale lembrar que na lição de Díaz a liberdade para todos os homens - necessidade primária da democracia - somente é atingível em modelos igualitários de sociedade, o que não sucede nos sistemas (neo)capitalistas.

No (Neo)Capitalismo a maioria da população torna-se classe espoliada, não tendo como gozar verdadeiramente da liberdade formal concedida pelas normas jurídicas. Sem 
igualdade material, a liberdade é privilégio de poucos, direito apenas daqueles que controlam o aparato estatal, verdadeiro monopólio das classes dominantes.

Se o único modo de tornar factível o exercício da soberania popular é a outorga ao maior número de cidadãos do direito de participar direta ou indiretamente na tomada de decisões político-estatais, pode-se concluir que o poder colossal dos "donos do dinheiro" (detentores dos "recursos políticos") perante as classes desfavorecidas faz com que a democracia se torne uma plutocracia.

A ausência de uma distribuição justa do poder econômico faz do direito de voto uma mera aparência, haja vista que os membros das classes subalternas raramente conseguem ingressar nos cardeais cargos público-eletivos. Simplificando os fatos, é plausível sinalar que em todas as sociedades capitalistas surgem duas classes de pessoas: uma classe que domina e uma que é dominada. A primeira classe, sempre menos numerosa, desempenha as funções políticas e monopoliza o poder. A segunda classe, a mais numerosa, é dirigida e controlada pela primeira.

Membros das classes favorecidas utilizam seus recursos para alcançarem o poder, isto é, utilizam de todos os artifícios de sua superioridade econômica para dominar o processo público-eletivo. Noutra vertente, os indivíduos das classes espoliadas não têm, na grande maioria das vezes, chances reais de disputar pelos cargos eletivos. Dessa feita, não é possível sustentar a marcha para uma igualdade maior na distribuição de "recursos políticos" sem uma profunda e equitativa distribuição, especialmente, de riqueza e de rendimento.

A governança da maioria, a democracia real, somente torna-se concreta quando a maioria dos homens participa - de fato - das decisões político-estatais. Esse momento social é alcançado, de acordo com Díaz, à medida que se implanta o Socialismo, modelo equânime de distribuição de riquezas, de direitos e de liberdades. Portanto, o primeiro obstáculo para alcançar uma democracia, o governo do povo, é eliminar o (Neo)Capitalismo, ou seja, extinguir a divisão social em classes.

Em harmonia com a doutrina de Elías Díaz, pode-se concluir afirmando que uma vez que a $\mathrm{CF} / 88$ adotou o sistema neocapitalista de produção, não há no Brasil uma democracia, mas sim um governo das elites econômicas. Dessa feita, para solução do problema, é crucial a implantação de um modelo socialista e, ademais, para que ele não se torne antidemocrático, é preciso que ele seja um socialismo democrático.

Observando as três perspectivas fundamentais do método democrático e realizando um paralelo com o socialismo, nota-se que há certa completude entre eles: $1^{\circ}$ ) democracia exige liberdade como autonomia, algo que o sistema socialista por ser um movimento que visa não 
somente à eliminação da exploração econômica, mas igualmente à emancipação do homem de todas as suas escravidões históricas, consegue efetivar; $2^{\circ}$ ) já que a democracia é a melhor resposta ao abuso de poder, então, uma vez que numa sociedade socialista os abusos de poder são tão possíveis quanto numa sociedade capitalista, eis por que o socialismo não deve afastar a soberania popular; $3^{\circ}$ ) por fim, se é verdadeira a afirmação de que a democracia é o melhor método para constatar, em certas circunstâncias, quais são os interesses coletivos, então não é possível imaginar como democracia e socialismo seriam conflitantes, posto que o sistema socialista visa satisfazer exatamente a vontade da maioria.

Nada obstante, o colapso da experiência do socialismo real no século XX fez surgir à ideia da incompatibilidade ad aeternum entre sociedade socialista e democracia. Contudo, não é metodologia válida atribuir uma relação límpida e transparente de causalidade entre teoria (compatibilidade entre socialismo e democracia) e fato histórico (não adesão do método democrático pelo socialismo real). A concepção da incompatibilidade entre soberania popular e sociedade socialista pertence nitidamente ao repertório ideológico das classes dominantes, querendo fazer crer que a essência do socialismo é o autoritarismo.

É preciso efetivar empiricamente os atributos do socialismo para permitir o incremento da soberania popular. Afinal, sem igualdade material, a tessitura político-estatal cinge-se nas mãos das classes privilegiadas, afastando a soberania da maioria. Eis a teoria: $\mathrm{O}$ socialismo é capaz de abrir os caminhos à democracia. Eis a prática: é preciso buscar o socialismo democrático.

\section{REFERÊNCIAS}

BASTOS, Celso Ribeiro; MARTINS, Ives Gandra. Comentários à Constituição do Brasil: Promulgada em 5 de outubro de 1988. v. 7: Arts. 170 a 192. 2 ed. atual. São Paulo: Saraiva, 2000.

BOBBIO, Norberto. Liberalismo e democracia. Tradução Marco Aurélio Nogueira. 6. reimpr. da 6. ed. de 1994. São Paulo: Brasiliense, 2006.

Qual socialismo? Debate sobre uma alternativa. Tradução Iza de Salles Freaza. 2. ed. Rio de Janeiro: Paz e Terra, 1983.

BONAVIDES, Paulo. Ciência Política. 18. ed. São Paulo: Malheiros, 2011.

CARVALHO, Kildare Gonçalves. Direito Constitucional: teoria do Estado e da Constituição. Direito Constitucional positivo. 12. ed. rev. e atual. Belo Horizonte: Del Rey, 2006. 
DAVID, René. Os grandes sistemas do Direito contemporâneo. Tradução Hermínio A. Carvalho. 3. ed. São Paulo: Martins Fontes, 1998.

DÍAZ, Elías. Curso de filosofía del derecho. Madrid: Marcial Pons, 1998.

. De la maldad estatal y la soberanía popular. Madrid: Debate, 1984.

2013.

El derecho y el poder: Realismo crítico y filosofía del derecho. Madrid: Dykinson,

Estado de Derecho y sociedad democrática. 6. ed. Madrid: Cuadernos para el dialogo, 1975.

Ética contra política: Los intelectuales y el poder. Madrid: Centro de Estudios Constitucionales, 1990.

1973.

La filosofía social del krausismo español. Madrid: Cuadernos para el dialogo,

La sociedad entre el derecho y la justicia. Barcelona: Salvat Editores, 1982a.

1987.

La transición a la democracia (Claves ideológicas, 1976-1986). Madrid: Eudema,

Legalidad-legitimidad en el socialismo democrático. Madrid: Civitas, 1977.

. Los viejos maestros: La reconstrucción de la razón. Madrid: Alianza, 1994.

Socialismo en España: el partido y el Estado. Madrid: Mezquita, 1982b.

Sociología y filosofía del derecho. Madrid: Taurus, 1982c.

Estado de Derecho y legitimidad democrática In: DÍAZ, Elías; COLOMER, José Luis (Eds.). Estado, justicia, derechos. Madrid: Alianza, 2011.

. Estado de Derecho In: DÍAZ, Elías; MIGUEL, Alfonso Ruiz (Eds.). Filosofía política II: Teoría del Estado. Madrid: Trotta, 2004.

Socialismo democrático y derechos humanos. In: ATIENZA, Manuel; PECESBARBA, G.; Díaz, Elías et. al. (Eds.). Política y Derechos Humanos. Valencia: Fernando Torres, 1976.

FIUZA, Ricardo Arnaldo Malheiros; COSTA, Mônica Aragão Martiniano Ferreira e. Aulas de teoria do Estado. 2. ed. rev., atual. e ampl. Belo Horizonte: Del Rey, 2007.

HELD, David. Modelos de Democracia. Tradução de Alexandre Sobreira Martins. Belo Horizonte: Paidéia, 1987.

HORTA, Raul Machado. Direito Constitucional. 2. ed. Belo Horizonte: Del Rey, 1999. 
HIERRO, Liborio L.; LAPORTA, Francisco J.; MIGUEL, Alfonso Ruiz (Eds.). Revisión de Elías Díaz: sus libros y sus críticos. Madrid: Centro de Estudios Políticos y Constitucionales, 2007.

LYRA FILHO, Roberto. O que é Direito. 2. reimpr. da 17. ed. de 1995. São Paulo: Brasiliense, 1999. (Coleção primeiros passos).

MARX, Karl; ENGELS, Friedrich. Manifesto do Partido Comunista. Tradução Pietro Nassetti. 2. ed. São Paulo: Martin Claret, 2011. (Coleção a obra-prima de cada autor).

MENDES, Gilmar Ferreira; COELHO, Inocêncio Mártires; BRANCO, Paulo Gustavo Gonet. Curso de Direito Constitucional. 4. ed. rev. e atual. São Paulo: Saraiva, 2009.

MORAES, Alexandre de. Direito Constitucional. 28. ed. rev. e atual. São Paulo: Atlas, 2012.

PEREIRA, Luiz (Org.). Perspectivas do Capitalismo Moderno: Leituras de Sociologia do Desenvolvimento. Rio de Janeiro: Zahar, 1971. (Biblioteca de Ciências Sociais).

PERRAULT, Gilles (Org.). O livro negro do capitalismo. Tradução Ana Maria Duarte et. al. 4. ed. Rio de Janeiro: Record, 2005.

RADBRUCH, Gustav. Filosofia do Direito. Tradução Marlene Holzhausen. 2. ed. São Paulo: WMF Martins Fontes, 2010. (Coleção biblioteca jurídica WMF).

RODRÍGUEZ, Aníbal D’Angelo. Diccionario Político. Buenos Aires: Claridad, 2004.

SILVA, José Afonso da. Comentário contextual à Constituição. 8. ed. atual. São Paulo: Malheiros, 2012.

SOTO, Fernando Bañuls. Elías Díaz, entre la Ética y la política. 2002. 455f. Tese (Doctorado) - Universidad de Alicante, Facultad de Derecho, Alicante. Disponível em: $<$ http://www.cervantesvirtual.com/obra/elias-diaz-entre-la-etica-y-la-politica--0/>. Acesso em: $17 / 10 / 2012$.

\title{
A PARALLEL BETWEEN THE POLITICAL-PHILOSOPHICAL CONCEPT OF DEMOCRACY SUSTAINED BY ELÍAS DÍAZ AND THE BRAZILIAN FEDERAL CONSTITUTION OF 1988
}

\begin{abstract}
The present paper aims at analyzing the political-philosophical concept of democracy defended by the Spanish philosopher Elías Díaz, that is, that democracy is incompatible with the (neo) capitalist system of production. Through the investigation of this theoretical postulate, it is intended to carry out a critical parallel with the Brazilian Federal Constitution of 1988, in order to deduce about the
\end{abstract}


vol. $11, \mathrm{n}^{\circ} 1$.

(im) possibility of embodiment of a democracy in the current Brazilian legal-political scenario.

Keywords: Democracy. (Neo) Capitalism. Socialism. Elías Díaz. Brazilian Federal Constitution of 1988. 